\title{
Physical Exercise and Self-Esteem in Women Facing Lockdown-Related Domestic Violence
}

\author{
Fabien D. Legrand ${ }^{1}$ (D) $\cdot$ Natacha Crombez-Bequet $^{1}$
}

Accepted: 10 August 2021 / Published online: 17 August 2021

(c) The Author(s), under exclusive licence to Springer Science+Business Media, LLC, part of Springer Nature 2021

\begin{abstract}
The purpose of the present brief report was to examine the effects of a 6-week long physical exercise program on global self-esteem and physical self-perceptions among women who faced lockdown-related domestic violence. Thirty-six domestic violence victims (mean age: $33.4 \pm 3.5$ yrs-old) were enrolled in this study. Participants were randomly and equally assigned to two intervention (physical exercise, counseling/support group therapy) and one control (no intervention) groups. The French version of the Physical Self-Perception Profile (ISP-25) was administered to all participants pre- and post-study. Mixed-design ANOVAs revealed significant Group by Time interactions for Global Self-Esteem, Physical Condition, and Body Attractiveness. Global Self-Esteem significantly improved in the two intervention groups, with a trend for better improvement in women who exercised compared to those who took part in support group meetings, Cohen's $d=0.68,95 \%$ confidence interval $[-0.18,1.54]$. On the other hand, only women from the Physical Exercise group reported significant gains in Physical Condition and Body Attractiveness. There was no change in any of the assessed variables for women in the control group. The present study provides new insights on the role of physical exercise in the understudied population of women with domestic violence. Our findings are discussed and related to previous studies.
\end{abstract}

Keywords Lockdown-related domestic violence $\cdot$ Self-esteem $\cdot$ Physical exercise

Adult domestic violence (sometimes referred to as family violence or domestic abuse) is defined as any incident or pattern of incidents of controlling, coercive or threatening behaviour, violence or abuse between people aged 18 or over who are or have been intimate partners or family members, regardless of gender or sexuality (Bewley \& Welch, 2014). This can include behaviors such as control over one's social interactions and autonomy, threats of abuse and violence, control of children and parenting, and verbal, emotional, or economic control.

France has one of the highest domestic violence (DV) rates in the European Union (EU), with an estimated $26 \%$ of French female respondents reporting one or more exposure to physical, psychological, or sexual abuse by a partner since the age of 15 (European Union Agency for Fundamental Rights, 2014). This number is 4 percentage

Fabien D. Legrand

fabien.legrand@univ-reims.fr

1 Department of Psychology, EA 6291 "Cognition, Health, and Society", University of Reims Champagne-Ardenne, 51100 Reims, France points above the EU average. There is much research indicating that DV has devastating effects not only on physical, but also on mental health (Pico-Alfonso et al., 2006), and emotional state (Siegel, 2013). In the current context of COVID-19 pandemic, successive lockdowns intended to stop the spread of the coronavirus have led to an increase in DV across the globe. The reasons for this have been explored recently (Singh, 2020) and mainly include increased alcohol use, financial difficulties, and extramarital relationships. In France, a first nationwide lockdown was introduced on March 16th 2020, and lasted for 9 weeks. Lockdown measures included travel bans, closure of nonessential commercial activities, suspension of schools and universities, and instructions for individuals to stay at home bar visits out for essential food shopping and exercise. The incidence of DV against women is estimated to have increased by 30\% during this period (UN Women, 2020).

As mentioned above, DV has devastating psychological consequences. Previous studies revealed that women's selfesteem is particularly influenced as a reaction to domestic violence (e.g., Kachaeva \& Shport, 2017; Zlotnick et al., 2006). This is especially true for verbal and sexual violence 
(Abani et al., 2012). Self-esteem describes a person's sense of value and worth based on self-evaluations (Rosenberg, 1965). It is a widely accepted idea that self-esteem is as a key indicator of emotional stability and is associated with mental health. For example, the vulnerability hypothesis of self-esteem states that low self-esteem might be predictive of developing psychopathology such as depression and anxiety (Van Tuijl et al., 2014). This is supported by research in various populations, showing associations between low selfesteem and development of depression, anxiety and overall lower well being (e.g., Sowislo \& Orth, 2013).

Sonstroem and Morgan (1989) developed a model which describes the relationship between physical exercise and self-esteem. Its revised form can be found in McAuley et al. (2005) and is shown in Fig. 1.

This model provides a framework that could explain how DV victims' direct experiences of physical activity may influence higher-order changes in self-esteem. Experiences in the physical activity context are proposed to influence perceptions of self-efficacy and to lead to higher level change in three subdomain perceptions of the physical self (physical condition, body attractiveness and strength), which may then generalise to improvement in an overall sense of physical self-worth. Change in physical self-worth may then generalise to global self-esteem change at the top of the hierarchy.

A meta-analysis conducted by Spence et al. (2005) revealed a significant positive effect of small magnitude for physical activity programs on global self-esteem $(d=0.23)$, with no difference in the efficacy of various types of exercise (aerobic, strength, martial arts, mix). No significant dose-response relationship for intensity, duration, or length of exercise programs has been identified. However, it has been suggested that more frequently performed exercise (i.e., 2-3 times per week) can result in greater self-esteem (Lindwall, 2013). In addition, moderation analyses indicated that individuals with low self-esteem might reap greater benefits from exercise (Spence et al., 2005).
To the best of our knowledge, no study examined the exercise effects on self-esteem with a special focus on victims of domestic violence. Yet, this population can be considered at greater risk for low self-esteem, as previously discussed. In this brief report, we aimed at evaluating the effects of physical exercise on self-esteem, as well as on the various subdomains of physical self-esteem, among women who have experienced domestic violence during the first COVID-19 lockdown in France.

\section{Materials and Methods}

\section{Sample Size Estimation}

Based on the findings from a recent study in a sample of French young adult women (Legrand et al., 2020), the effect size for changes in global self-esteem following an exercise program can be expected to be moderate-to-large $(d=0.62)$. Based on this anticipated effect size, it was estimated that for a study including three groups and two times of measurements, with a two-sided significance level of 5\% and statistical power fixed at $80 \%$, the needed total sample size of participants was 30 (G*POWER; Faul et al., 2007).

\section{Participants}

Thirty-six participants (mean age: $33.4 \pm 3.5$ yrs-old) were recruited from consenting women who filed for domestic violence in the commonwealth of Reims, Chalons, and Epernay (Marne, Northeastern France) at the CIDFF-51 between March 2020 and Februay 2021. The CIDFF-51 is a nonprofit organization based in Chalons (Marne, Northeastern France) which brings assistance to domestic violence victims. It can provide referrals to help obtain orders of protection, legal services, emergency shelters, etc.

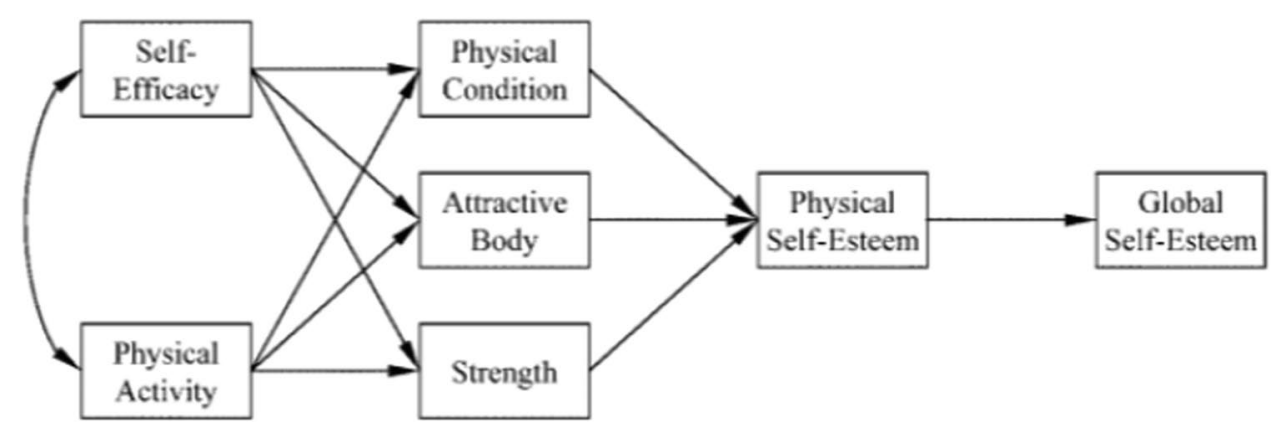

Fig. 1 Revised version of the Exercise and Self-Esteem Model. Note. From "Physical Activity, Self-Efficacy, and Self-Esteem: Longitudinal Relationships in Older Adults", by E. McAuley, S. Elavsky, R. W. Motl, J. F. Konopack, L. Hu, and D. X. Marquez, 2005, Journal of Gerontology, 608(5), p. 269 (https://doi.org/10.1093/geronb/60.5. p268). Copyright 2005 by the Gerontological Society of America. Reprinted with permission 
Two trained CIDFF-51 staff members recruited participants into the study by purposive sampling based on a set of inclusion criteria. The main inclusion criteria were as follows: 1/ being a woman aged 18 years or over, 2/ having experienced domestic violence at some time in the past 6 months, 3/ not being physically active on a regular basis (inactive), and 4/ absence of contraindication to exercise (e.g., significant cardiovascular, musculoskeletal or neurological disease). Being inactive was defined as reporting less than 20 min of moderate-vigorous physical activity per day during the last year.

Within the six months prior to starting the study, over a third of recruited women $(36.1 \%)$ had been on psychiatric medication, nearly a fifth $(19.4 \%)$ had attempted suicide, and over half (52.8\%) had used police services. Most women $(86.1 \%)$ had children. Just under a fifth of women $(19.4 \%)$ had left school aged 16 or younger. Those who had attended university totalled $30.6 \%$, illustrative of domestic violence cutting across education levels. In terms of work, $30.6 \%$ of women were employed full-time or self-employed, $52.8 \%$ worked part-time, and $16.6 \%$ were unemployed. The length of time women experienced domestic violence ranged from 6 months to 13 years, with the average being 2.6 years $(S D=0.9)$.

No permission from the local ethics committee was asked for, since only biomedical clinical studies come within the competence of ethic committees according to French law. However, written informed consent was obtained from all participants and the study was conducted in accordance with the Declaration of Helsinki, as revised in 2008.

\section{Procedure and Measures}

The present study design included three arms (two intervention arms): Physical Exercise (Group A), Counseling/ Support Group (Group B), and No Intervention (Control, Group C). Random allocation to each group was done in a 1:1:1 ratio at the end of an initial telephone interview by one of the authors who was unaware of participants' identity. A permutated block design with a block size of three was used. For each participant in Groups A and B, the assigned intervention was started the week following the initial interview, and lasted 6 weeks.

Participants in the Physical Exercise group had to perform a 25 min walking/running bout, along with 10 min of strength training (pushups, planks, side planks) for a total of 35-40 min of activity. This was done two days per week at a moderate-to-vigorous intensity (Rating of Perceived Exertion of 13-15 on a 20-point scale; RPE-15; Borg, 1982), as recommended to improve self-perceptions (e.g., Lox et al., 2020). All training sessions were conducted individually and supervised by sports sciences students at participants' residence or workplace. Students were provided with special authorizations to move to participants' location during lockdown.

The Counseling/Support Group consisted of weekly sessions of 80 min duration, with a psychologist and two former domestic violence victims who acted as group moderators. Sessions intented to be educational and therapeutic. Educational elements included information on resources and services, as well as on legal and financial issues. Therapeutic elements were the exchange of personal experience, facilitation of expressed emotion, and task accomplishment to build self-efficacy. Sessions included two to five participants each.

Women in the control group received no intervention, but they were offered the chance of receiving one of the two interventions at the end of the study.

All participants took the ISP-25 (Ninot et al., 2000) at the beginning (pre) and at the end of the study period (post). The ISP-25 is a French adaptation of the Physical Self Perception Profile (PSPP, Fox \& Corbin, 1989). This instrument has 25 items for which respondents have to circle the appropriate figure on a scale of 1 (not at all) to 6 (very much). The ISP-25 has 6 subscales, five of which are similar to those found in the current EXSEM model: (a) Global Self-Esteem (five items, $\alpha=0.77$ ), (b) Physical Self-Esteem (five items, $\alpha=0.85$ ), (c) Physical Condition (five items, $\alpha=0.89$ ), (d) Strength (three items, $\alpha=0.86$ ), and (e) Body Attractiveness (three items, $\alpha=0.76$ ).

\section{Data Analysis}

A mixed design with two independent variables was used: (a) one between-participant variable (Group A, Group B, Group C), and (b) one within-participant variable (pre- and poststudy assessments). There were five dependent variables: (a) Global Self-Esteem, (b) Physical Self-Esteem, (c) Physical Condition, (d) Strength, and (e) Body Attractiveness.

Therefore a series of five 3 (Groups) $\times 2$ (Time Points) mixed-design ANOVAs were conducted. The significance level was $\alpha=0.05$. Significant interactions were further analyzed on the individual variables using Bonferroni-corrected $t$-tests.

Effect sizes, Cohen's $d=\left(\mathrm{M}_{\mathrm{i}}-\mathrm{M}_{\mathrm{j}}\right) / \mathrm{SD}_{\text {pooled }}$, were computed to compare the magnitude of the difference in the mean change score for each dependent variable. Because in studies with small samples Cohen's $d$ relies on a nonrobust measure of central tendency (mean), and a non-robust measure of dispersion (SD), it is a non-robust (i.e., biased) measure of effect size. Therefore, in accordance with previous recommendations (e.g., McGraw \& Wong, 1992), biascorrected estimators of Cohen's $d s$ along with their 95\% confidence intervals (95\% CIs) were calculated using the online calculator by Lenhard and Lenhard (2016). 
One-way ANOVA and Chi-2 tests were also performed to assess whether there were baseline differences between groups.

\section{Results}

Thirty-two of the 36 participants (i.e., 88.9\%) completed both pre- and post-intervention questionnaires (11 in Group A, 11 in Group B, and 10 in Group C). Figure 2 shows the CONSORT study flow chart. Considering the low dropout rate (4 out of 36), only per-protocol analyses are reported here.

Chi squares and ANOVA revealed no baseline differences between groups for duration of domestic violence exposure, length of school education, employment status, psychiatry diagnostic/treatment history, or family composition.

The average number of exercise sessions attended for the participants in the exercise group was 10 (i.e., 83.3\%), and 8 of the 11 participants (i.e., $72.7 \%$ ) missed no session.

Table 1 presents pre- and post-study statistics for all ISP-25 measures in each group. There was a significant Group $\times$ Time interaction for Global Self-Esteem, $F(2$, $29)=5.42, p=0.010, \eta^{2}=0.054$. More specifically, post-hoc comparisons indicated that for participants in both interventions (Physical Exercise and Counseling/Support Group), scores for Global Self-Esteem significantly increased preto post-study ( $41.8 \%$ and $21.7 \%$ respectively), whereas it remained statistically unchanged in the control group

Fig. 2 Flowchart of study participants through the trial

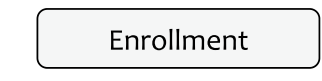

$(-0.6 \%)$. The effect size comparing the impact of the two intervention groups revealed an almost significant difference favoring Physical Exercise over Support Group, Cohen's $d=0.68,95 \%$ CI $[-0.18,1.54]$.

Two other significant Group $\times$ Time interactions were found for Physical Condition $(F(2,29)=3.54, p=0.042$, $\left.\eta^{2}=0.034\right)$ and Body Attractiveness $(F(2,29)=4.36$, $\left.p=0.022, \eta^{2}=0.037\right)$, indicating that scores increased by a greater amount for participants in the Physical Exercise intervention (Group A) compared to participants in Groups $\mathrm{B}$ and C. Post-hoc tests revealed no significant difference in Groups B and C when comparing pre- and post-study mean values. In contrast, significant improvements were found for these two variables in Group A (Physical Condition: $30.2 \%$, and Body Attractiveness: 24.2\%).

No significant Group $\times$ Time interaction effects were oberved for any of the other dependent variables (Physical Self-Esteem and Strength).

\section{Discussion}

To the best of our knowedge, this is the first study evaluating the effects of physical exercise training on self-esteem in domestic violence victims. We compared the effects of a 6-weeks long exercise training program to those observed following well-established group cognitive-behavioral treatment (counseling/support group) or no intervention (control

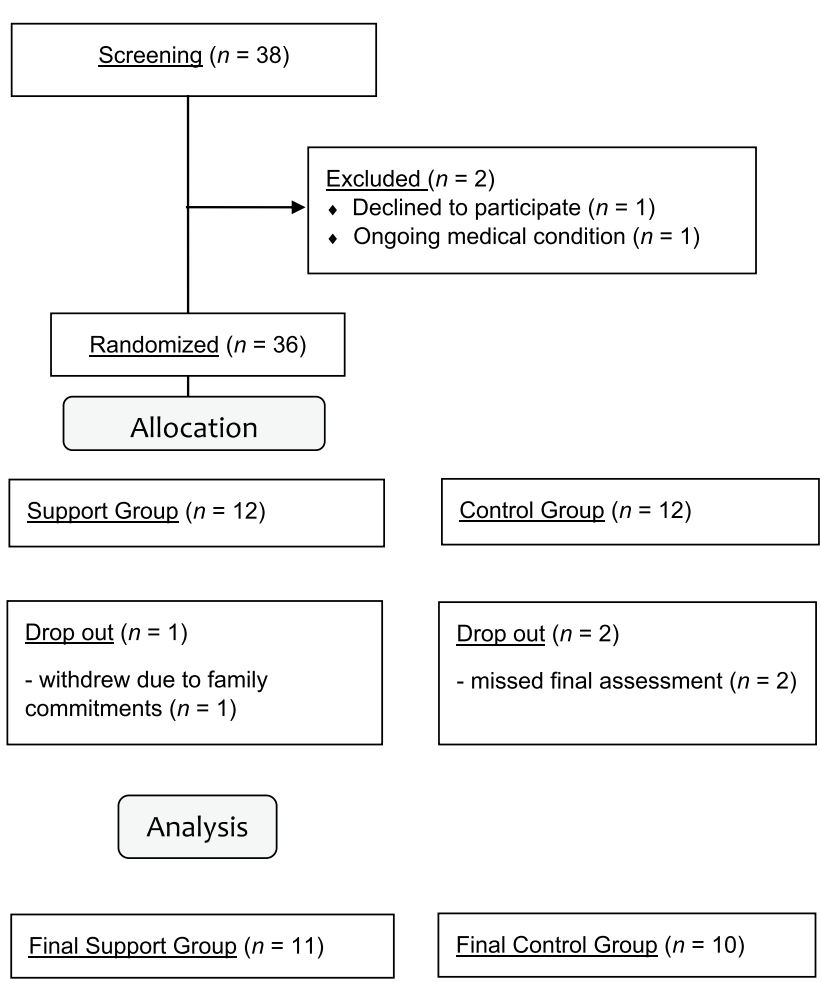


Table 1 Observed means for the ISP-25 subscales, ANOVA results, and effect sizes of the differences between the two intervention groups (Physical Exercise vs. Control) on the change scores

\begin{tabular}{|c|c|c|c|c|c|c|}
\hline & \multicolumn{2}{|c|}{ Pre-study } & \multicolumn{2}{|c|}{ Post-study } & \multirow{2}{*}{$\begin{array}{l}F_{(2,29)} \\
\text { Time } \times \text { Group }\end{array}$} & \multirow[t]{2}{*}{ Cohen's $d[95 \% \mathrm{CI}]$} \\
\hline & $M$ & $S D$ & $M$ & $S D$ & & \\
\hline Global Self-Esteem & & & & & $5.42 * *$ & $0.85[0.51,2.45]$ \\
\hline Physical Exercise & 16.91 & 6.35 & 24.00 & 6.18 & & \\
\hline Support Group & 15.09 & 5.75 & 18.36 & 6.62 & & \\
\hline Control & 15.40 & 4.84 & 15.30 & 5.33 & & \\
\hline Physical Self-Esteem & & & & & 2.50 & $0.72[-0.04,1.75]$ \\
\hline Physical Exercise & 18.27 & 6.87 & 22.73 & 5.35 & & \\
\hline Support Group & 14.00 & 5.88 & 14.55 & 5.94 & & \\
\hline Control & 14.40 & 4.19 & 14.90 & 4.82 & & \\
\hline Physical Condition & & & & & $3.24 *$ & $0.75[0.06,1.87]$ \\
\hline Physical Exercise & 15.91 & 8.47 & 20.36 & 6.42 & & \\
\hline Support Group & 11.46 & 6.39 & 11.18 & 5.36 & & \\
\hline Control & 11.60 & 4.95 & 10.70 & 5.12 & & \\
\hline Strength & & & & & 1.16 & $0.61[-0.46,1.26]$ \\
\hline Physical Exercise & 7.82 & 4.16 & 9.27 & 4.34 & & \\
\hline Support Group & 6.55 & 3.20 & 6.64 & 2.34 & & \\
\hline Control & 8.20 & 2.25 & 8.80 & 2.04 & & \\
\hline Body Attractiveness & & & & & $4.36^{*}$ & $0.79[0.20,2.04]$ \\
\hline Physical Exercise & 11.27 & 3.13 & 14.00 & 2.41 & & \\
\hline Support Group & 10.91 & 3.51 & 10.64 & 4.61 & & \\
\hline Control & 10.50 & 3.21 & 10.80 & 2.78 & & \\
\hline
\end{tabular}

group) using a true experimental design with repeated measurements (pre- and post-study).

In accordance with the existing literature (e.g., Spence et al., 2005), our findings support the positive effect of physical exercise training on global self-esteem; with the exercise group showing more positive changes compared to the support group (where the changes were less positive but still significant) and to the control group (where no improvement was observed). However, the extent to which physical exercise increased global self-esteem $(d=0.85)$ is markedly higher than usually seen in samples of participants without history of domestic violence (mean effect size of 0.23 in the meta-analysis by Spence et al., 2005). The larger effect size reported here could be due to a potential ceiling effect bias in previous studies. Indeed, for years, research in this area has primarily included young participants (especially university students) who generally have greater self-esteem and are more positive about the future (Stainton-Roger \& Stainton-Roger, 2001). Scoring high on a self-esteem scale at baseline leaves little room for improvement.

The trend for a larger magnitude of intervention effects on global self-esteem in women who exercised compared to those who participated in support group meetings can be explained in terms of the EXSEM model (Sonstroem \& Morgan, 1989; McAuley et al., 2005). The main focus of activities conducted in the physical exercise intervention (walking/running sessions, strength exercises) was on building endurance, helping with weight loss, and toning muscles. As a result, it is no surprise that significant improvements were detected in most physical self-esteem subdomains (except Strength) for women in this group, which was not seen in women who have been part of the counseling/support group. As proposed by the EXSEM model, improved perception of one's physical abilities translates into positive changes in global self-esteem.

Of particular note is that in the present study, the second largest effect size in terms of exercise influence was for Body Attractiveness (Cohen's $d=0.79$ ). This stands in contradiction with previous research which emphasized that this variable was the least influenced by exercise (e.g., Lindwall \& Hassmen, 2004; Megakli et al., 2017). At this stage, no interpretation can be offered for this intriguing result, but it could be explained by the strong correlation usually noted between body attractiveness and global selfesteem (Harter, 1990). This explanation was supported by our findings since the change score for Body Attractiveness was strongly and positively associated with the change score for Global Self-Esteem in women who exercised, $r=0.86, p<0.001,95 \%$ CI $[0.54,0.96]$ and in women who participated in support groups, $r=0.69, p=0.017,95 \% \mathrm{CI}$ $[0.17,0.92]$. On the other hand, no association was found between these variables in women from the control group, $r=0.13, p=0.731,95 \%$ CI $[-0.55,0.70]$. 
Some possible ways to implement physical activity services into women's everydaylife can be suggested here. Examples of settings for low-cost or free physical activity in communities include places of worship, and nonprofit fitness centers. Places of worship are community anchors for many minority groups and can promote exercise by providing positive role models, and peer-led exercise classes. Likewise, nonprofit fitness centers (such as YMCA's and YWCA's) have been traditional sites for exercise promotion and fitness programs with comprehensive facilities, flexible hours of operation, classes for beginners, and low-cost or free child care services. Because lack of confidence is a key symptom of people with low self-esteem, fitness instructors may find it difficult to trigger interest to exercise in DV victims. However, a study conducted in routine practice for mental health patients from both hospital and day-care centers has provided promising evidence (Sørensen, 2006). Particularly, exercise participation was predicted solely by intrinsic regulation, reflecting inherent pleasure and participation for its own sake (Sørensen, 2006). To this extent, autonomy supportive environments, providing options for the type and duration of exercise, which promote intrinsically regulated exercise behavior (Ryan \& Deci, 2000), might trigger interest in eligible but reluctant to exercise women.

Although encouraging, these preliminary findings come with some limitations. First, our results were obtained on a relatively small number of participants and obviously need to be confirmed in larger and more diverse samples of domestic violence victims. For example, as our sample was exclusively composed of women, we are not able to elaborate on the effects of physical exercise training in domestic violence male victims. Second, further research is required to clarify which type of exercise is most beneficial for the respective subdomains of physical self-esteem.

Despite these limitations, the present brief report provides new insights on the role of physical exercise in the understudied population of women with domestic violence. Benefits of exercise appeared to be more prominent than in previous studies of similar intent conducted with other groups. Our findings underscore the significant role that physical activity plays in the psychological well-being of DV female victims. Short-term aerobic exercise interventions may be more effective in promoting DV victims' self-esteem than usual interventions are. This is of crucial importance for DV victims since, as already mentioned, self-esteem is a major constituent of psychological health and well-being, and its violation has serious consequences for a wide range of psychological processes. In addition, some past studies have indicated that low self-esteem represents an obstacle in the search for social support in women facing DV (Abadi et al., 2012). Therefore, participation in low- to moderateintensity supervised physical exercise programs should be encouraged in this population. Such programs can be found for free or minimal cost through places of worship or nonprofit fitness centers. Alternatively, delivering exercise programs as online video tutorials could also be suggested, as it may allow DV victims to practice these exercises in the comfort of their own homes and at a time that is convenient to them.

\section{Declarations}

Conflict of Interest We have no conflicts of interest to disclose.

\section{References}

Abadi, M. N. L., Ghazinour, M., Nojomi, M., \& Richter, J. (2012). The buffering effect of social support between domestic violence and self-esteem in pregnant women in Teheran Iran. Journal of Family Violence, 27, 225-231. https://doi.org/10.1007/ s10896-012-9420-x.

Bewley, S., \& Welch, J. (2014). The ABC of domestic and sexual violence. John Wiley \& Sons.

Borg, G. A. (1982). Psychophysical bases of perceived exertion. Medicine \& Science in Sports \& Exercise, 14, 377-381.

European Union Agency for Fundamental Rights (2014). Violence against women: an EU-wide survey. Main results report. Luxembourg: Publications Office of the European Union. https://fra. europa.eu/en/publication/2014/violence-against-women-eu-widesurvey-main-results-report. Accessed 12 June 2021

Faul, F., Erdfelder, E., Lang, A. G., \& Buchner, A. (2007). G*Power 3: A flexible statistical power analysis program for the social, behavioral, and biomedical sciences. Behavioral Research Methods, 39, 175-191. https://doi.org/10.3758/bf03193146.

Fox, K. R., \& Corbin, C. B. (1989). The physical self-perception profile: Development and preliminary validation. Journal of Sport \& Exercise Psychology, 11, 408-430.

Harter, S. (1990). Causes, correlates, and the functional role of global self-worth: A life-span perspective. In R. J. Sternberg \& J. Kolligian (Eds.), Competence considered (pp. 67-97). Yale University Press.

Kachaeva, M., \& Shport, S. (2017). Psychological and psychiatric consequences of violence against women. European Psychiatry, 41(Supp. 1), s904. https://doi.org/10.1016/j.eurpsy.2017.01.1851.

Legrand, F. D., Silete, G., \& Schiffler, F. (2020). Internalized mediaromoted body ideals only marginally moderate the effects of exercise on self-esteem, body image satisfaction, and physical self-perceptions. Research Quarterly for Exercise \& Sport, 91, 713-719. https://doi.org/10.1080/02701367.2019.1706713.

Lenhard, W. \& Lenhard, A. (2016). Calculation of Effect Sizes. Psychometrica. Retrieved April 3, 2021, from: https://www.psychometr ica.de/effect_size.html

Lindwall, M. (2013). Exercise, self-esteem, and self-perceptions. In D. Tod \& D. Lavallee (Eds.), Psychology of strength and conditioning (pp. 82-108). Routledge.

Lindwall, M., \& Hassmen, P. (2004). The role of exercise and gender for physical self-perceptions and importance ratings in Swedish university students. Scandinavian Journal of Medicine \& Science in Sports, 14, 373-380. https://doi.org/10.1046/j.1600-0838.2003. 372.x.

Lox, C. L., Martin-Ginis, K. A., Gainforth, H. L., \& Petruzzello, S. J. (2020). The psychology of exercise: Intergrating theory and practice (5th ed.). Routledge. 
McAuley, E., Elavsky, S., Motl, R. W., Konopack, J. F., Hu, L., \& Marquez, D. X. (2005). Physical activity, self-efficacy, and selfesteem: Longitudinal relationships in older adults. Journal of Gerontology, 608, 268-275. https://doi.org/10.1093/geronb/60.5. p268.

McGraw, K. O., \& Wong, S. P. (1992). A common language effect size statistic. Psychological Bulletin, 111, 361-365. https://doi.org/10. 1037/0033-2909.111.2.361.

Megakli, T., Vlachopoulos, S. P., Thogersen-Ntoumani, C., \& Theodorakis, Y. (2017). Impact of aerobic and resistance exercise combination on physical self-perceptions and self-esteem in women with obesity with one-year follow-up. International Journal of Sport \& Exercise Psychology, 15, 236-257. https://doi.org/10.1080/16121 97X.2015.1094115.

Ninot, G., Delignières, D., \& Fortes, M. (2000). L'évaluation de l'estime de Soi dans le domaine corporel [Self-esteem evaluation in the physical activity domain]. Sciences \& Techniques Des Activités Physiques Et Sportives, 53, 35-48.

Pico-Alfonso, M. A., Garcia-Linares, M. I., Celda-Navarro, N., BlascoRos, C., Echeburúa, E., \& Martinez, M. (2006). The impact of physical, psychological, and sexual intimate male partner violence on women's mental health: Depressive symptoms, posttraumatic stress disorder, state anxiety, and suicide. Journal of Women's Health, 15, 599-611. https://doi.org/10.1089/jwh.2006.15.599.

Rosenberg, M. (1965). Society and the adolescent self-image. Princeton University Press.

Ryan, R. M., \& Deci, E. L. (2000). Self-determination theory and the facilitation of intrinsic motivation, social development, and wellbeing. American Psychologist, 55, 68-78. https://doi.org/10.1037/ 0003-066X.55.1.68.

Siegel, J. P. (2013). Breaking the links in intergenerational violence: An emotional regulation perspective. Family Process, 52, 163-178. https://doi.org/10.1111/famp.12023.

Singh, M. (2020). Domestic harassment of women and children during COVID-19. European Journal of Molecular \& Clinical Medicine, 7, 754-761.

Sørensen, M. (2006). Motivation for physical activity of psychiatric patients when physical activity was offered as part of treatment.
Scandinavian Journal of Medicine \& Science in Sports, 16, 391398. https://doi.org/10.1111/j.1600-0838.2005.00514.x.

Sowislo, J. F., \& Orth, U. (2013). Does low self-esteem predict depression and anxiety? A meta-analysis of longitudinal studies. Psychological Bulletin, 139, 213-240. https://doi.org/10.1037/a0028931.

Spence, J. C., McGannon, K. R., \& Poon, P. (2005). The effect of exercise on global self-esteem: A quantitative review. Journal of Sport \& Exercise Psychology, 27, 311-334. https://doi.org/10. 1123/jsep.27.3.311.

Stainton-Roger, W., \& Stainton-Roger, R. (2001). The psychology of gender and sexuality. Open University Press.

United Nations for Gender Equality and the Empowerment of Women (UN Women) (2020). COVID-19 and ending violence against women and girls. Retrieved June 12, 2021, from https://www. unwomen.org/-/media/headquarters/attachments/sections/libra ry/publications/2020/issue-brief-covid-19-and-ending-violenceagainst-women-and-girls-en.pdf?la $=$ en $\& v s=5006$

Van Tuijl, L. A., De Jong, P. J., Sportel, B. E., De Hullu, E., \& Nauta, M. H. (2014). Implicit and explicit self-esteem and their reciprocal relationship with symptoms of depression and social anxiety: A longitudinal study in adolescents. Journal of Behavior Therapy \& Experimental Psychiatry, 45, 113-121. https://doi.org/10.1016/j. jbtep.2013.09.007.

Viero, A., Barbara, G., Montisci, M., Kustermann, K., \& Cattaneo, C. (2020). Violence against women in the Covid-19 pandemic: A review of the literature and a call for shared strategies to tackle health and social emergencies. Forensic Science International, 319, 110650. https://doi.org/10.1016/j.forsciint.2020.110650.

Zlotnick, C., Johnson, D. M., \& Kohn, R. (2006). Intimate partner violence and long-term psychosocial functioning in a national sample of American women. Journal of Interpersonal Violence, 21, 262-275. https://doi.org/10.1177/0886260505282564.

Publisher's Note Springer Nature remains neutral with regard to jurisdictional claims in published maps and institutional affiliations.

This study was registered with ClinicalTrials.gov (identifier NCT04875494). 